\title{
KAJIAN SISTEM DRAINASE PERUMAHAN VALLE VERDE DI DESA PASIRHALANG
}

\author{
Fuad Hasan \\ Program Studi Teknik Sipil \\ Universitas Widyatama \\ hasan.fuad@widyatama.ac.id
}

\begin{abstract}
Abstrak
Drainase merupakan salah satu fasilitas dasar yang dirancang sebagai sistem guna memenuhi kebutuhan masyarakat dan merupakan komponen penting dalam perencanaan kota maupun perumahan. Perumahan Valle Verde yang berlokasi di Desa Pasir Halang Kecamatan Cisarua Kabupaten Bandung Barat perlu membuat kajian sistem drainase agar terhindar dari bencana banjir atau genangan air hujan. Tujuan dari kajian ini yaitu untuk mengetahui debit puncak dan kapasitas sistem drainase rencana. Dalam kajian ini analisis yang dilakukan adalah zona drainase, curah hujan, curah hujan rata-rata kawasan, pemilihan jenis distribusi hujan, perhitungan waktu konsenstrasi, menentukan besarnya intensitas hujan pada kala ulang 2 tahun, perhitungan debit banjir dan perhitungan kapasitas saluran rencana. Dari hasil analisis dan perhitungan tersebut diketahui bahwa untuk saluran drainase utama dapat menggunakan saluran terbuka dengan dimensi tinggi $\mathrm{H}=0,22 \mathrm{~m}$ dan lebar dasar $\mathrm{B}=$ $0,25 \mathrm{~m}$ serta tinggi jagaan $\mathrm{W}=0,20 \mathrm{~m}$. Adapun untuk saluran yang berada didalam komplek, dapat menggunakan saluran tertutup dengan dimensi diameter $\mathrm{D}=0.30 \mathrm{~m}$.
\end{abstract}

Kata kunci :

Sistem drainase, debit puncak, channel

\begin{abstract}
Drainage is one of the basic facilities designed as a system to meet the needs of the community and is an important component in urban and residential planning. Valle Verde Residential located in the village of Pasirhalang, Cisarua District, Kabupaten Bandung Barat needs to make a study of the drainage system in order to avoid flooding or inundation. The
\end{abstract}

purpose of this study is to determine the peak discharge and drainage system capacity of the plan. In this study the analysis carried out is the drainage zone, rainfall, average rainfall in the area, choosing the type of rainfall distribution, calculating the time concentration, determining the amount of rainfall intensity at the return period of 2 years, calculating flood discharge and calculating the capacity of the planned channel. From the results of the analysis and calculation it is known that for the main drainage channel can use an open channel with dimensions of height $0.25 \mathrm{~m}$ and $a$ base width $0.30 \mathrm{~m}$ and freeboard $0.20 \mathrm{~m}$. As for channels that are in residential areas, can use closed channels with diameter dimensions $D$ $=0.30 \mathrm{~m}$.

Keywords :

Drainage system, peak discharge, channel

\section{Pendahuluan}

Drainase merupakan salah satu fasilitas dasar yang dirancang sebagai sistem guna memenuhi kebutuhan masyarakat dan merupakan komponen penting dalam perencanaan kota. Perumahan adalah kelompok rumah yang berfungsi sebagai lingkungan tempat tinggal atau lingkungan hunian yang dilengkapi dengan prasarana dan sarana lingkungan. Perumahan Valle Verde yang berlokasi di Desa Pasir Halang Kecamatan Cisarua Kabupaten Bandung Barat adalah perumahan sebagai salah satu pertumbuhan fisik dalam suatu wilayah yang merupakan kebutuhan dasar manusia. Dalam membangun perumahan, perlu dipertimbangkan pula perencanaan drainasenya. Drainase yang kurang baik akan mengakibatkan berbagai macam masalah yang bisa merugikan manusia itu sendiri. Salah satunya adalah masalah banjir. Oleh karena itu, kajian sistem drainase dalam

Fuad Hasan

Jurnal Ilmiah Teknologi Informasi Terapan

Volume 8, No 1, 15 Desember 2021 
perumahan Valle Verde ini perlu mendapat perhatian yang penting guna terhindar dari bencana banjir atau genangan air hujan, serta mendukung kehidupan manusia yang hidup bermukim di perumahan tersebut dengan nyaman dalam kehidupan sehari - hari.

\section{KAJIAN LITERATUR}

Kajian ini dilaksanakan di Perumahan Valle Verde Desa Pasirhalang Kabupaten Bandung Barat. Lokasi kajian dapat dilihat pada gambar berikut.

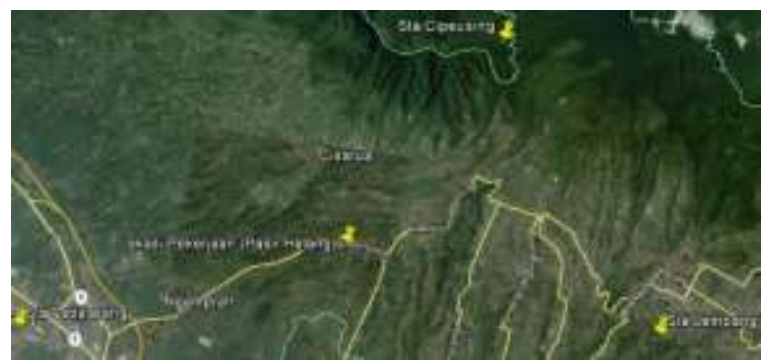

Gambar 1. Orientasi lokasi pekerjaan

Untuk menganalisis kondisi hidrologi di wilayah kajian diperlukan data hujan dari stasiun pengamatan terdekat di sekitarnya yaitu stasiun hujan Padalarang, Cipeusing, dan Lembang. Data hujan harian maksimum yang tersedia di stasiun hujan tersebut adalah dari tahun 2002-2013.

Kondisi topografi lahan merupakan hal yang paling mendasar dalam kajian sistem tata air. Dari peta topografi, kondisi kontur elevasi kawasan dapat diamati sehingga dapat ditentukan arah aliran air suatu sistem tata air yang terencana. Berdasarkan hasil survey lapangan, daerah ini memiliki topografi yang sangat cukup curam. Perbedaan ketinggian lahan bervariasi, karena dibeberapa lokasi dalam area perumahan yang akan dibangun sudah berpetak-petak. Luas area perumahan ini adalah sebesar $\pm 2,83$ hektar dengan rincian komposisi penggunaan lahan sebagai berikut.
Tabel 1. Komposisi penggunaan lahan

\begin{tabular}{|c|l|c|c|c|}
\hline No & \multicolumn{1}{|c|}{ Penggunaan Lahan } & Luas (m2) & Luas tutup (m2) & Luas buka (m2) \\
\hline A & Kavling & & & \\
\hline 1 & Kavling tipe A & 3801 & 1330 & 2471 \\
\hline 2 & Kavling tipe B & 8120 & 3000 & 5120 \\
\hline 3 & Kavling komersil & 1218 & 490 & 728 \\
\hline B & Fasos & & & \\
\hline 1 & Mushola dll & 1045 & 280 & 765 \\
\hline 2 & Jalan (aspal/paving block) & 7172 & 3586 & 3586 \\
\hline C & RTH & & & \\
\hline 1 & Ruang Terbuka Hijau & 6921 & 0 & 6921 \\
\hline & & & & \\
\hline D & Luas Total & $\mathbf{2 8 2 7 7}$ & $\mathbf{8 6 8 6}$ & $\mathbf{1 9 5 9 1}$ \\
\hline
\end{tabular}

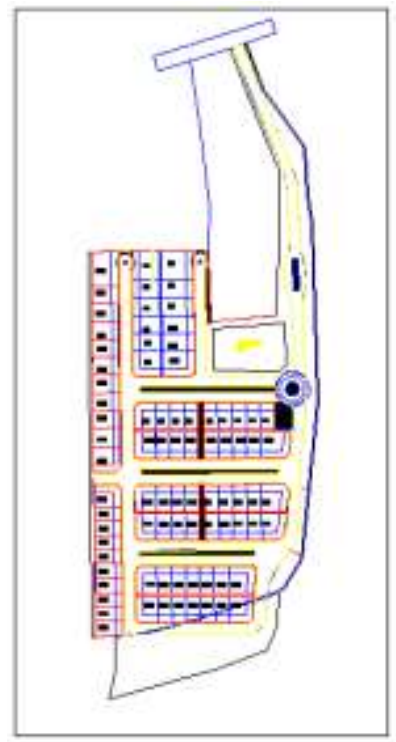

Gambar 2. Layout perumahan

\section{MetodologI}

Proses untuk menyelesaikan penelitian ini dijelaskan sebagai berikut :

1. Persiapan

2. Pengumpulan data sekunder (keadaan lokasi eksisting, peta topografi dan data hidrologi)

3. Identifikasi lapangan (survey kondisi drainase eksisting dan survey aliran)

4. Analisa hidrologi (curah hujan rencana dan intensitas hujan)

5. Analisa hidrolika kondisi rencana

6. Kesimpulan dan saran

Fuad Hasan

Jurnal Ilmiah Teknologi Informasi Terapan

Volume 8, No 1, 15 Desember 2021 


\section{ANALISIS DAN PEMBaHasan}

\section{IV.1 Kondisi Umum Lokasi Kajian}

Kajian ini dilakukan di daerah Perumahan Valle Verde Desa Pasirhalang Kabupaten Bandung Barat dengan luas keseluruhan sebesar $\pm 2,83$ hektar. Kondisi eksisting lahan yang ada merupakan tanah terbuka yang siap dibangun perumahan.

\section{IV.2 Zona Drainase}

Luas daerah tangkapan air untuk perumahan ini adalah sebesar $\pm 2,83$ hektar dengan rincian komposisi penggunaan lahan seperti pada tabel 1 . Zona drainase di kawasan perumahan ini dibagi menjadi 10 zona, pembagian zona ini didasarkan pada kondisi kebutuhan saluran.

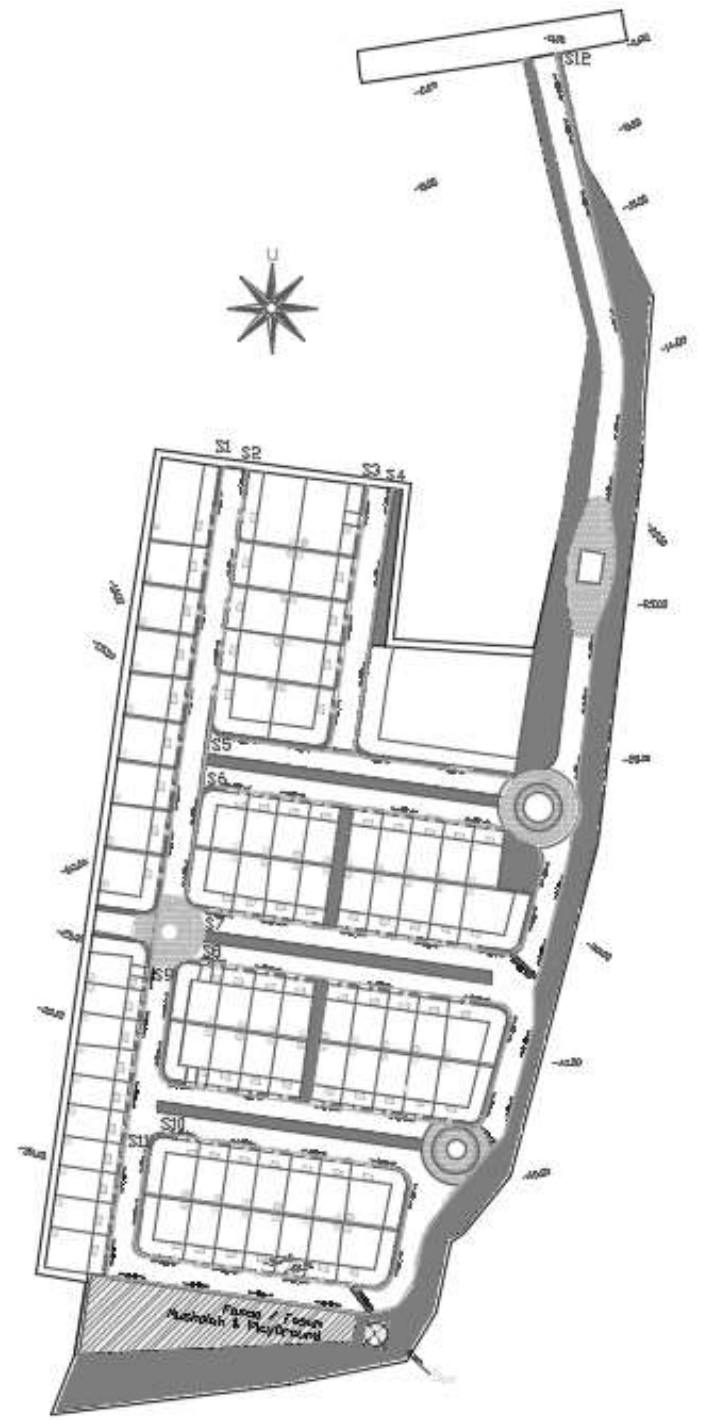

Gambar 3. Pembagian Zona Drainase

Luas masing-masing zona serta koefisien aliran dapat dilihat pada tabel 2. Adapun saluran yang direncanakan dapat dilihat pada tabel 3 .

Tabel 2. Luas Zona \& Koefisien Aliran Gabungan

\begin{tabular}{|c|l|c|c|c|}
\hline No & \multicolumn{1}{|c|}{ Komposisi } & Luas (m2) & Nilai C & C fraksi \\
\hline 1 & Atap & 5100 & 0.95 & 0.17 \\
\hline 2 & Jalan aspal & 7172 & 0.7 & 0.18 \\
\hline 3 & Open space & 9084 & 0.25 & 0.08 \\
\hline 4 & Ruang Terbuka Hijau & 6921 & 0.2 & 0.05 \\
\hline & & & & \\
\hline & Total & $\mathbf{2 8 2 7 7}$ & Cgab & $\mathbf{0 . 4 8}$ \\
\hline
\end{tabular}

Fuad Hasan

Jurnal Ilmiah Teknologi Informasi Terapan

Volume 8, No 1, 15 Desember 2021 
Tabel 3. Data Saluran yang Direncanakan

\begin{tabular}{|c|c|c|c|c|c|}
\hline Saluran & Elev max & Elev min & Delta $h$ & Panjang $(\mathrm{m})$ & Panjang $(\mathrm{km})$ \\
\hline $\mathrm{s} 1$ & -8.6 & -48.47 & 39.87 & 280.67 & 0.28 \\
\hline $\mathrm{s} 2$ & -8.6 & -24.22 & 15.62 & 112.89 & 0.11 \\
\hline $\mathrm{s} 3$ & -8.91 & -18.77 & 9.86 & 69.40 & 0.07 \\
\hline $\mathrm{s} 4$ & -9.4 & -19 & 9.6 & 69.40 & 0.07 \\
\hline $\mathrm{s} 5$ & -19.92 & -29.44 & 9.52 & 75.64 & 0.08 \\
\hline $\mathrm{s} 6$ & -17.14 & -34.44 & 17.3 & 115.12 & 0.12 \\
\hline $\mathrm{s} 7$ & -24.22 & -34.33 & 10.11 & 84.11 & 0.08 \\
\hline $\mathrm{s} 8$ & -25.78 & -37.89 & 12.11 & 115.93 & 0.12 \\
\hline $\mathrm{s} 9$ & -25.78 & -37.89 & 12.11 & 108.58 & 0.11 \\
\hline s10 & -32.66 & -48.47 & 15.81 & 101.40 & 0.10 \\
\hline s11 & -32.66 & -48.47 & 15.81 & 83.33 & 0.08 \\
\hline s12 (utama) & 0 & -48.47 & 48.47 & 345.78 & 0.35 \\
\hline
\end{tabular}

\section{IV.3 Curah Hujan Rencana}

Analisis dilakukan dengan menggunakan data curah hujan harian dari tahun 2002 hingga 2013 milik Stasiun Badan Meteorologi, Klimatologi, dan Geofisika (BMKG). Data curah hujan yang diperlukan dalam perancangan drainase adalah data curah hujan dari stasiun pencatat curah hujan di sekitar atau terdekat lokasi studi. Data curah hujan harian maksimum selama 12 tahun dapat dilihat pada Tabel 4.

Tabel 4. Data curah hujan maksimum harian

\begin{tabular}{|c|c|c|c|}
\hline \multirow{2}{*}{ Tahun } & \multicolumn{3}{|c|}{ Stasiun Curah Hujan (mm/hari) } \\
\cline { 2 - 4 } & Padalarang & Cipeusing & Lembang \\
\hline 2002 & 88.2 & 40.0 & 64.0 \\
\hline 2003 & 67.0 & 12.0 & 75.5 \\
\hline 2004 & 56.0 & 13.0 & 82.0 \\
\hline 2005 & 81.0 & 31.0 & 88.0 \\
\hline 2006 & 48.5 & 22.0 & 79.5 \\
\hline 2007 & 69.0 & 54.0 & 79.0 \\
\hline 2008 & 90.0 & 48.0 & 72.0 \\
\hline 2009 & 75.0 & 37.3 & 78.1 \\
\hline 2010 & 51.4 & 29.0 & 69.7 \\
\hline 2011 & 223.5 & 222.5 & 140.0 \\
\hline 2012 & 68.9 & 49.5 & 75.4 \\
\hline 2013 & 62.6 & 30.0 & 94.0 \\
\hline
\end{tabular}

Perkiraan hujan rencana didapatkan dari analisis frekuensi dengan kemungkinan tertinggi pada periode tertentu. Hasil analisis frekuensi berfungsi sebagai dasar perhitungan untuk mengantisipasi setiap kemungkinan yang akan terjadi. Analisis frekuensi dapat dilakukan dengan metoda distribusi probabilitas antara lain Distribusi Normal, Distribusi Log Normal, Distribusi Log-Person III, dan Distribusi Gumbel
(Triatmodjo 2010). Kala ulang yang digunakan untuk menghitung nilai hujan rencana yaitu 2, 5, 10, 20, 25, dan 50 tahun. Hasil analisis frekuensi curah hujan rencana dapat dilihat pada Tabel 5.

Tabel 5. Hasil analisis curah hujan rencana

\begin{tabular}{|c|c|c|c|c|}
\hline \multirow{2}{*}{$\begin{array}{c}\text { Probabilitas } \\
\text { (tahun) }\end{array}$} & \multicolumn{4}{|c|}{ Curah Hujan Rencana (mm/hari) } \\
\cline { 2 - 5 } & Normal & Log Normal & Gumbel & Log Pearson III \\
\hline 2 & 71.29 & 65.73 & 64.76 & 57.76 \\
\hline 5 & 104.77 & 89.47 & 99.91 & 78.27 \\
\hline 10 & 122.27 & 105.11 & 123.19 & 101.78 \\
\hline 20 & 136.72 & 120.08 & 145.51 & 135.00 \\
\hline 25 & 140.93 & 124.82 & 152.59 & 148.40 \\
\hline 50 & 152.99 & 139.48 & 174.41 & 201.09 \\
\hline
\end{tabular}

Hasil perhitungan nilai curah hujan rencana dari setiap metode memiliki nilai yang berbeda sehingga harus diuji kesesuaiannya dengan sifat masing-masing jenis distribusi. Hasil uji kecocokan metode analisa curah hujan maksimum menggunakan Smirnov Kolmogorov dapat dilihat pada Tabel 6.

Tabel 6. Uji Smirnov-Kolmogorov

\begin{tabular}{|c|c|c|c|c|c|}
\hline No. & Metode & Do & D kritik & Syarat & Keterangan \\
\hline 1 & Normal & 0.359 & \multirow{4}{*}{0.38} & \multirow{4}{*}{ Do $<$ D kritik } & Diterima \\
\hline 2 & Log-Normal & 0.278 & & & Diterima \\
\hline 3 & Gumbel & 0.289 & & & Diterima \\
\hline 4 & Log Pearson III & 0.223 & & & Diterima \\
\hline
\end{tabular}

Dari uji kecocokan metode analisa curah hujan maksimum di atas dapat diketahui bahwa Metode Log-Pearson III memiliki deviasi yang paling kecil di antara metode- metode yang lain. Dapat dilihat pada tabel bahwa nilai Dmaks $=0.223<$ Dkritik $=0.380$. Sehingga analisa curah hujan dengan Metode LogPearson III inilah yang dipakai sebagai curah hujan rencana untuk perencanaan sistem drainase.

\section{IV.4 Waktu Konsentrasi}

Perhitungan selanjutnya yaitu mencari waktu konsentrasi masing-masing saluran dengan menggunakan persamaan Kirpich. Rekapitulasi data saluran yang direncanakan ditampilkan dalam tabel 3 .

Data hujan yang ada adalah data hujan maksimum harian rata-rata, sehingga dalam perhitungan intensitas hujan menggunakan rumus dari Mononobe, yang mana lamanya hujan diasumsikan sama dengan nilai waktu konsentrasi. Adapun dalam pemilihan periode ulang, untuk ukuran DAS kurang dari $10 \mathrm{Ha}$ dipakai periode ulang 2 tahun. Hasil

Fuad Hasan

Jurnal Ilmiah Teknologi Informasi Terapan

Volume 8, No 1, 15 Desember 2021 
perhitungan waktu konsentrasi dan intensitas hujan lainnya dapat dilihat pada tabel 7 .

Tabel 7. Hasil Perhitungan Waktu Konsentrasi dan Intensitas Hujan

\begin{tabular}{|c|c|c|c|c|c|}
\hline Saluran & $\mathrm{L}(\mathrm{m})$ & So & $\mathrm{Tc}(\mathrm{jam})$ & $\mathrm{R}(\mathrm{mm})$ & $\mathrm{I}(\mathrm{mm} / \mathrm{jam})$ \\
\hline 1 & 280.67 & 0.142 & 0.053 & 57.76 & 142.16 \\
\hline 2 & 112.89 & 0.138 & 0.026 & 57.76 & 225.37 \\
\hline 3 & 69.40 & 0.142 & 0.018 & 57.76 & 291.30 \\
\hline 4 & 69.40 & 0.138 & 0.018 & 57.76 & 289.30 \\
\hline 5 & 75.64 & 0.126 & 0.020 & 57.76 & 270.15 \\
\hline 6 & 115.12 & 0.150 & 0.026 & 57.76 & 227.89 \\
\hline 7 & 84.11 & 0.120 & 0.022 & 57.76 & 252.82 \\
\hline 8 & 115.93 & 0.104 & 0.030 & 57.76 & 206.83 \\
\hline 9 & 108.58 & 0.112 & 0.028 & 57.76 & 217.54 \\
\hline 10 & 101.40 & 0.156 & 0.023 & 57.76 & 245.54 \\
\hline 11 & 83.33 & 0.190 & 0.019 & 57.76 & 285.61 \\
\hline 12 & 345.78 & 0.140 & 0.062 & 57.76 & 127.29 \\
\hline
\end{tabular}

\section{IV.5 Debit Puncak Pada Masing-Masing Zona}

Debit puncak dihitung dengan menggunakan rumus Metode Rasional :

$\mathrm{Q}=0,002778 \times \mathrm{C} \times \mathrm{I} \times \mathrm{A}$

dengan :

$\mathrm{Q}=$ debit maksimum $(\mathrm{m} 3 / \mathrm{dt})$

$\mathrm{C}=$ koefisien limpasan

$\mathrm{I}=$ Intensitas curah hujan rata-rata $(\mathrm{mm} / \mathrm{jam})$

$\mathrm{A}=$ luas daerah pengaliran $(\mathrm{Ha})$

Hasil perhitungan debit puncak dengan data intensitas hujan pada masing-masing zona dapat dilihat pada Tabel 8 .
Tabel 8. Perhitungan Debit Puncak

\begin{tabular}{|c|c|c|c|c|}
\hline Saluran & $\mathrm{C}$ & $\mathrm{I}(\mathrm{mm} / \mathrm{jam})$ & $\mathrm{A}(\mathrm{m} 2)$ & $\mathrm{Q}(\mathrm{m} 3 / \mathrm{s})$ \\
\hline 1 & 0.40 & 142.16 & 6934.69 & 0.11 \\
\hline 2 & 0.49 & 225.37 & 2169.34 & 0.07 \\
\hline 3 & 0.52 & 291.30 & 1234.69 & 0.05 \\
\hline 4 & 0.47 & 289.30 & 363.02 & 0.01 \\
\hline 5 & 0.50 & 270.15 & 1996.20 & 0.07 \\
\hline 6 & 0.49 & 227.89 & 1821.49 & 0.06 \\
\hline 7 & 0.51 & 252.82 & 1850.21 & 0.07 \\
\hline 8 & 0.49 & 206.83 & 2117.52 & 0.06 \\
\hline 9 & 0.50 & 217.54 & 2013.44 & 0.06 \\
\hline 10 & 0.50 & 245.54 & 1656.84 & 0.06 \\
\hline 11 & 0.52 & 285.61 & 1370.33 & 0.06 \\
\hline 12 & 0.48 & 127.29 & 28277 & 0.48 \\
\hline
\end{tabular}

\section{IV.6 Analisa Saluran}

Dengan mengetahui debit aliran pada potongan saluran drainase maka dapat direncanakan dimensi saluran yang ekonomis sebagai berikut (dengan asumsi saluran berbentuk trapesium).

Debit aliran $(\mathrm{Q}) \quad$ = variasi

Kemiringan saluran $(S) \quad=$ variasi

Koefisien kekasaran $(\mathrm{n})=0.013 \quad$ (menggunakan saluran beton)

$$
\begin{aligned}
& \mathrm{Q}=\mathrm{A} \times \mathrm{V} \\
& Q=h^{2} \sqrt{3} \frac{1}{n}\left(\frac{h}{2}\right)^{\frac{2}{3}} S^{\frac{1}{2}} \\
& b=\frac{2}{3} h \sqrt{3}
\end{aligned}
$$

dengan :

$\mathrm{Q}=$ debit aliran pada saluran $(\mathrm{m} 3 / \mathrm{dt})$

$\mathrm{V}=$ kecepatan aliran $(\mathrm{m} / \mathrm{dt})$

$\mathrm{A}=$ luas penampang basah saluran (m2)

$\mathrm{h}=$ tinggi air $(\mathrm{m})$

$\mathrm{b}=$ lebar dasar $(\mathrm{m})$

Fuad Hasan 
Tabel 9. Perhitungan Debit Yang Mengalir Pada Saluran

\begin{tabular}{|c|c|c|}
\hline Saluran & Debit yang mengalir & Qrancangan $(\mathrm{m} 3 / \mathrm{s})$ \\
\hline 1 & $\mathrm{Q} 1+\mathrm{Q} 2$ & 0.18 \\
\hline 2 & $\mathrm{Q} 2$ & 0.07 \\
\hline 3 & $\mathrm{Q} 3$ & 0.05 \\
\hline 4 & $\mathrm{Q} 4$ & 0.01 \\
\hline 5 & $\mathrm{Q} 3+\mathrm{Q} 4+\mathrm{Q} 5$ & 0.14 \\
\hline 6 & $\mathrm{Q} 6$ & 0.06 \\
\hline 7 & $\mathrm{Q} 7$ & 0.07 \\
\hline 8 & $\mathrm{Q} 8$ & 0.06 \\
\hline 9 & $\mathrm{Q} 9$ & 0.06 \\
\hline 10 & $\mathrm{Q} 10$ & 0.06 \\
\hline 11 & $\mathrm{Q} 11$ & 0.06 \\
\hline 12 & Qall & 0.48 \\
\hline
\end{tabular}

Perhitungan dimensi saluran dilakukan dengan metode trial and error untuk mendapatkan dimensi saluran yang ekonomis. Perhitungan dimensi saluran dapat dilihat pada tabel 10 dan tabel 11 .

Tabel 10. Perhitungan Dimensi Saluran Terbuka

\begin{tabular}{|c|c|c|c|c|}
\hline Saluran & $Q(\mathrm{~m} 3 / \mathrm{s})$ & $H(\mathrm{~m})$ & Qkap $(\mathrm{m} 3 / \mathrm{s})$ & $\mathrm{B}(\mathrm{m})$ \\
\hline 1 & 0.18 & 0.15 & 0.20 & 0.17 \\
\hline 2 & 0.07 & 0.11 & 0.09 & 0.13 \\
\hline 3 & 0.05 & 0.10 & 0.07 & 0.12 \\
\hline 4 & 0.01 & 0.10 & 0.07 & 0.12 \\
\hline 5 & 0.14 & 0.14 & 0.16 & 0.16 \\
\hline 6 & 0.06 & 0.10 & 0.07 & 0.12 \\
\hline 7 & 0.07 & 0.11 & 0.08 & 0.13 \\
\hline 8 & 0.06 & 0.11 & 0.08 & 0.13 \\
\hline 9 & 0.06 & 0.11 & 0.08 & 0.13 \\
\hline 10 & 0.06 & 0.10 & 0.07 & 0.12 \\
\hline 11 & 0.06 & 0.10 & 0.08 & 0.12 \\
\hline 12 & 0.48 & 0.22 & 0.55 & 0.25 \\
\hline
\end{tabular}

Tabel 11. Perhitungan Dimensi Saluran Tertutup

\begin{tabular}{|c|c|c|c|c|c|}
\hline Saluran & $\mathrm{Q}(\mathrm{m} 3 / \mathrm{s})$ & Dia $(\mathrm{m})$ & $\mathrm{A}(\mathrm{m} 2)$ & $\mathrm{P}(\mathrm{m})$ & $\begin{array}{c}\text { Qkap }(\mathrm{m} 3 / \mathrm{s}) \\
\text { Saluran Tertutup }\end{array}$ \\
\hline 1 & 0.18 & 0.30 & 0.07 & 0.30 & 0.35 \\
\hline 2 & 0.07 & 0.30 & 0.07 & 0.30 & 0.34 \\
\hline 3 & 0.05 & 0.30 & 0.07 & 0.30 & 0.35 \\
\hline 4 & 0.01 & 0.30 & 0.07 & 0.30 & 0.34 \\
\hline 5 & 0.14 & 0.30 & 0.07 & 0.30 & 0.32 \\
\hline 6 & 0.06 & 0.30 & 0.07 & 0.30 & 0.36 \\
\hline 7 & 0.07 & 0.30 & 0.07 & 0.30 & 0.31 \\
\hline 8 & 0.06 & 0.30 & 0.07 & 0.30 & 0.28 \\
\hline 9 & 0.06 & 0.30 & 0.07 & 0.30 & 0.30 \\
\hline 10 & 0.06 & 0.30 & 0.07 & 0.30 & 0.37 \\
\hline 11 & 0.06 & 0.30 & 0.07 & 0.30 & 0.42 \\
\hline 12 & 0.48 & 0.40 & 0.13 & 0.40 & 0.82 \\
\hline
\end{tabular}

Dari hasil analisa dan perhitungan tersebut diketahui bahwa untuk saluran drainase utama (S12) dapat menggunakan saluran terbuka dengan dimensi tinggi $\mathrm{H}=0,22 \mathrm{~m}$ dan lebar dasar $\mathrm{B}=0,25 \mathrm{~m}$ serta tinggi jagaan $\mathrm{W}=0,20 \mathrm{~m}$. Adapun untuk saluran yang berada didalam komplek (S1-S11) dimensi saluran ekonomis dapat menggunakan saluran tertutup dengan diameter $\mathrm{D}=0.30 \mathrm{~m}$.

\section{KESIMPULAN DAN SARAN}

Berdasarkan hasil analisa dan perhitungan pada penelitian ini dapat disimpulkan sebagai berikut :

1. Debit maksimum yang terjadi pada Perumahan Valle Verde adalah sebesar $0.48 \mathrm{~m} 3 / \mathrm{s}$ yaitu yang terjadi pada saluran $\mathrm{S} 12$.

2. Dimensi saluran ekonomis untuk saluran drainase utama (S12) adalah dengan menggunakan saluran terbuka dengan tinggi $\mathrm{H}=0.22 \mathrm{~m}$ dan lebar dasar $\mathrm{B}=0.25 \mathrm{~m}$ serta tinggi jagaan $\mathrm{W}=0.20 \mathrm{~m}$.

3. Diusulkan untuk pelaksanaan di lapangan menggunakan dimensi saluran dengan tinggi air $\mathrm{H}=0.25 \mathrm{~m}$ dan lebar dasar $\mathrm{B}=0.30 \mathrm{~m}$ serta tinggi jagaan $\mathrm{W}=0.20 \mathrm{~m}$.

4. Berdasarkan analisa hidrolika yang telah diketahui, debit kapasitas dari saluran tertutup dengan diameter $0.30 \mathrm{~m}$ dapat menampung debit hujan yang mengalir di saluran. Oleh karena itu dimensi saluran ekonomis untuk saluran lainnya (S1-S11) yaitu dengan menggunakan saluran tertutup dengan diameter $\mathrm{D}=0.30 \mathrm{~m}$.

\section{REFERENSI}

[1] Hasan, Fuad, Bambang Eko Widyanto, Raden Herdian Bayu Ash Siddiq. 2019. Studi Respon Daerah Aliran Sungai Cimanyar Terhadap Berbagai Kejadian Hujan. Jurnal Ilmiah Teknologi Informasi Terapan.

[2] Sutoyo. 2018. Study of the Drainage System in Pemuda Street, Bogor City. Jurnal Teknik Sipil Dan Lingkungan.

[3] Triatmodjo B. 2010. Hidraulika II. Yogyakarta (ID): Beta Offset

[4] Widodo E, Ningrum D. 2015. Evaluasi Sistem Jaringan Drainase Permukiman Soekarno Hatta Kota Malang dan Penanganannya. Jurnal Ilmu-Ilmu Teknik. 11(3):6-8

Fuad Hasan

Jurnal Ilmiah Teknologi Informasi Terapan

Volume 8, No 1, 15 Desember 2021 